\title{
Economic impacts of Japan's renewable energy sector and the feed-in tariff system: using an input-output table to analyze a next-generation energy system
}

\author{
Satoshi Nakano ${ }^{1} \cdot$ Sonoe Arai $^{2} \cdot$ Ayu Washizu ${ }^{3}$
}

Received: 3 June 2015/Accepted: 20 April 2016/Published online: 3 May 2016

(C) The Author(s) 2016. This article is published with open access at Springerlink.com

\begin{abstract}
We construct an input-output table to analyze a next-generation energy system. Based on this table, we estimate the effect of using renewable energy on Japan's economic structure as well as the feed-in tariff's contribution to the cost structure. The results clearly show that, induced by demand, existing power generation options and the production of existing passenger vehicles would be reduced and replaced by electric vehicles (EVs), plug-in hybrid vehicles (PHVs), and the renewable energy sector. Furthermore, the demand for production in the supply chain of these sectors would change. While the feed-in tariff seems to benefit the overall Japanese economy, the benefits are not divided equally among the sectors because the positive effect of the feed-in tariff system is greater than the negative effect in energy and energy-intensive industries, while the negative effect is greater in the service sectors, on which the cost of the feed-in tariff system is levied. However, renewable-energy-induced service activities, such as research and business services, are becoming more pervasive. Therefore, this inequality may be resolved in the long term and could be assisted by policies that accelerate this change.
\end{abstract}

Keywords Input-output table $\cdot$ Renewable energy $\cdot$ Economic structure $\cdot$ Feed-in tariff

Ayu Washizu

washizu@waseda.jp

1 The Japan Institute for Labour Policy and Training, 4-8-23, Kamishakujii, Nerimaku, Tokyo 177-8502, Japan

2 The Research Institute of Economy, Trade \& Industry, IAA, 1-3-1, Kasumigaseki, Chiyodaku, Tokyo 100-8901, Japan

3 Waseda University, 1-6-1, Nishiwaseda Shinjyuku, Tokyo 169-8050, Japan 


\section{Introduction}

In 2011, Japan introduced a feed-in tariff system (a special act for the procurement of renewable energy from providers; henceforth, FIT system) for renewable energy, thus, bringing renewable energy to the attention of electric power suppliers. An FIT system for renewable energy implies that the state guarantees the purchase of renewable energy power at a specific price that is revised every year based on the prevalent socioeconomic conditions. This approach allows for an increase in investment in renewable energy power facilities because it guarantees the recovery of the fixed costs involved in exploiting such resources (ANRE 2013). The aim of a FIT system is to increase investment in renewable energy.

Furthermore, as renewable energy is often variable and produced in small-scale, dispersed locations, utility grid reform is essential for its promotion. Currently, such reform is being promoted on three fronts: (a) expansion of the power network, which is now divided into regions; (b) de-regulation of the generation and sale of power; and (c) guarantee of the neutrality of electricity transmission and distribution by legally separating it from electricity generation (MITI 2013).

Because energy composition is a fundamental issue for a country's economic structure, we construct an input-output table to analyze a next-generation energy system (http://www.f.waseda.jp/washizu/table.html) and to investigate the economic effects of developing renewable energy resources and separating electricity generation and transmission/distribution. Thus, the first goal of this study is to explain the creation of the input-output table. Based on this table, we then estimate the changes in the economic structure that would result from the use of renewable energy as well as the contribution of an FIT system to the cost structure in various sectors.

Section 2 reviews previous studies on renewable energy using input-output analysis and summarizes the major concerns and methodological issues; Sect. 3 provides an overview and summary of our extended tables; and Sect. 4 summarizes the results of the open static input-output analysis. Section 5 considers the effects of the FIT system on the cost structure of the overall Japanese economy using a Leontief price model, and finally, Sect. 6 concludes the paper. The details on the construction of the extended tables are presented in the Appendix.

\section{Issues in renewable energy using input-output analysis}

Energy conservation and identifying alternative energy sources to combat global warming have become increasingly important issues. Input-output analyses have frequently been conducted to identify current energy consumption structures and to examine the effectiveness of energy policies. Park and Heo (2007) estimate the quantities of direct and indirect energy inputs in household consumption and conduct factor analyses on the fluctuations over time. Furthermore, they highlight the problem of valuing energy inputs using uniform prices in a published inputoutput table. Guo et al. (2010) integrate trade and energy statistics as well as inputoutput tables for China and the United States in a mutually comparable format. They 
then compare the contribution of trade to global $\mathrm{CO}_{2}$ emissions in the two countries and show that their sectorial approach has important policy implications. Lindner et al. (2013) split the national input-output table of China's energy sector into a distribution sector and eight generation sectors based on regional tables, which provides more refined results for greenhouse gas emissions from Chinese exports. Additionally, Zeng et al. (2014) conduct a factor analysis of the changes in energy consumption per unit of GDP in China using input-output tables. In their model, household consumption is treated as an endogenous variable, and the authors show the tremendous effects of improvements in sectorial energy efficiency.

The aforementioned studies calculate the effects of changes in the economic structure or policy on energy consumption and $\mathrm{CO}_{2}$ emissions. However, inputoutput analyses are often used to measure how changes in the energy consumption structure affect the overall economy. Particularly in Europe, there is extensive research investigating the direct and indirect effects of the increased use of renewable energy on employment. Madlener and Koller (2007) calculate the effects of introducing biomass heating systems on Australia's economy and $\mathrm{CO}_{2}$ emissions. Lehr et al. (2008) construct a macroeconomic model that incorporates an inputoutput table with renewable energy sectors wherein they add new renewable energy sectors to Germany's original input-output table based on interviews with business operators. The results from their econometric model clearly show the advantage of a renewable energy policy over the long term (30-50 years). Neuwahl et al. (2008) assemble input-output tables from 25 EU countries and, by disaggregating seven sectors, such as fossil fuels and biofuels, they calculate the effect on employment of an EU biofuel policy. They also consider the effects of substitution between biofuels and foodstuffs. The results show that policies that encourage the use of biofuels have a neutral effect on employment, seemingly because the efficiency gains in one sector offset the efficiency losses in others. This finding hints at the necessity of sector-level thinking, for which input-output analyses are well suited. Caldés et al. (2009) use an input-output analysis to calculate the effects of constructing and operating solar thermal plants in Spain on employment. De Arce et al. (2012) calculate the input-output effects of plans for renewable energy over the medium and long term in Morocco using a dynamic variant input-output model, and they anticipate that Morocco's current economic structure will gradually shift toward that of France. Cai et al. (2011), Wang et al. (2013), and Cai et al. (2014) calculate the effects of investment in green energy in China and use input-output tables to split the electric power (column) sector into nine sub-sectors to calculate the indirect effects on employment. They find that while using renewable energies has a clear effect on employment, they also note the possibility of mismatch problems due to educational levels and gender differences. Lambert and Silva (2012) investigate the effects of renewable energy on employment at the national level and find that the input-output relationship has a significant effect on national employment. In Japan, Ishikawa et al. (2014) focus on the effects of renewable energy promotion policies on the local economy of the Fukushima area, which was damaged by the nuclear accident. Nakano et al. (2015) calculate the amount of output, employment, energy, and $\mathrm{CO}_{2}$ emissions induced by the construction and operation of a power plant 
fueled by unused woody biomass, and they also estimate the amount of public benefit obtained from preserving forests.

Other input-output analyses examine the effects of greenhouse gas (GHG) emissions as life cycle assessment (LCA) studies. Crawford (2009) calculates the effect on life cycle energy of increased investment in wind turbines in Australia using documents on turbines and an input-output table. Using an environmentally extended, multi-regional input-output model, Bright and Strømman (2010) investigate the effects of biofuel production from Scandinavian forest resources and its consumption by road transport on reducing GHG emissions. Acquaye et al. (2011) conduct a hybrid LCA analysis using biodiesel process data and a UK inputoutput table to show the features of carbon emission hot spots caused by biodiesel production. Matsumoto and Hondo (2011) and Hienuki and Hondo (2013) examine the employment effects of the introduction of renewable energy for the Japanese case by applying hybrid LCA methods.

In summary, because energy is one of the most important inputs in all sectors, much attention is paid to the effects of energy investment on the economy that result from sectorial interdependence. Recent studies have also examined the effects of using renewable energy on employment and $\mathrm{CO}_{2}$ emissions, emphasizing the increases and decreases at the macro level as well as the large effects in certain sectors. In addition, many studies use process data to separate the energy sector, and electricity generation in particular, from the original sectors in published inputoutput tables.

When analyzing energy and environmental problems using input-output tables, it is important to consider that each sector's input structure has a significant effect on the overall empirical results. Using even a small amount of proxy information, the disaggregation of original sectors improves the accuracy of input-output multipliers. This finding has been demonstrated in numerical experiments by Lenzen (2011), while Su et al. (2010) and Zhou et al. (2013) demonstrate the same finding in empirical analyses.

In Japan, the Embodied Energy and Emission Intensity Data for Japan using input-output tables (3EID; Sector 403), published by the National Institute for Environmental Studies, provides the input-output data. These data can be used in environmental analyses. However, 3EID does not segregate renewable energy. NISTEP (2013) developed investment composition vectors of renewable energy power plants for the Japanese government's input-output table, but it did not compile an extended matrix table. With regard to the FIT system and the reform of the power sector, the focus has been on how the economy and environment might be affected by introducing renewable energy and legally separating electricity generation and transmission/distribution. Therefore, this study constructs an input-output table to analyze a next-generation energy system as well as its economic effects. We now describe the database and present the results after analyzing the data. 


\section{Overview of the input-output table to analyze a next-generation energy system}

The input-output table uses the Japanese government's 2005 input-output table and divides the electric power sector into an electricity generation sector and an electricity transmission/distribution sector. The electricity generation sector is then further divided into nuclear, thermal, and hydro power. Finally, activities are added to the table, such as renewable energy facility construction and renewable energy power generation. Renewable energy power generation is defined as those activities that intend to sell electricity using the FIT (Institute for Economic Analysis of Nextgeneration Science and Technology 2015).

We divide a producer's price of electricity in the 2005 input-output table into two parts: the producer's price of electricity $(10.773 \mathrm{JPY} / \mathrm{kWh})$ and the price of the transmission/distribution service $(5.3789 \mathrm{JPY} / \mathrm{kWh}){ }^{1}$ Because the price of electricity in our table has been uniformly estimated as the producer's price of electricity (10.773 JPY/kWh), electricity transactions in physical units (kWh) can be converted back at this price. The difference between the FIT for a renewable energy power producer and the producer's price is shown as a negative in the value-added row. That is, we treat the FIT as a subsidy. Sectors that consume electricity are understood to pay this electricity price $(10.773 \mathrm{JPY} / \mathrm{kWh})$ together with the transmission/distribution cost $(5.3789 \mathrm{JPY} / \mathrm{kWh})$. We incorporate sectors such as electricity transmission/distribution, renewable energy facility construction, renewable energy power generation, and electric/hybrid vehicles into the original 108 sectors in the published input-output table.

The following three tables are provided as input-output tables for the analysis:

I. Electrical transmission/distribution sectors for 2005: this table separates out the electricity transmission/distribution sector from the electricity sector in the published 2005 table.

II. Extended renewable energy sectors for 2005 (hereafter, the "Extended table for 2005"): this table incorporates activities such as renewable energy power generation and renewable energy facility construction into the table "Electrical transmission/distribution sectors for 2005." The renewable energy power generation figures are the actual data for 2005.

III. Extended renewable energy sectors for 2030 (hereafter, the "Extended table for 2030"): this table divides the 2005 total production of electricity based on the ratio of electricity generation assumed for 2030 in the "Information on renewable energy" published by the Energy and Environment Council (Energy and Environment Council 2012b). In other words, this table reflects the hypothetical situation where the ratio of electricity generation for 2030, including renewables, had been implemented in 2005.

\footnotetext{
1 According to "Itemized accounts of operating expenses from 10 power and electricity companies," approximately two-thirds of the total cost borne by electricity companies is for generation, while the remainder is for transmission/distribution.
} 
In the Appendix, we briefly explain how these tables are constructed.

The "Extended table for 2030" has substantial limitations, as the inter-sectorial linkages will change enormously by 2030 to reflect possible changes in social conditions such as population aging. Furthermore, the utilization of renewable energy will require various changes in inter-sectorial linkages, and the cost composition of renewable energy facility construction and operations will change dramatically as well. The "Extended table for 2030" thus cannot reflect such changes and instead makes general suppositions for a society using renewable energy. Accordingly, the statistical information in the extended tables must be continuously updated.

\section{Economic impact of electricity production from renewable energy}

Using Leontief inverse matrices from the extended tables, the induced effect on the economy of introducing renewable energy power was calculated as follows:

$$
x=(I-(I-\hat{M}) A)^{-1}(I-\hat{M}) F D
$$

where $x$ is the induced output vector (in millions of JPY), $A$ is the input coefficient matrix, and FD is the vector of final demand (in millions of JPY). Then, $A$ is a

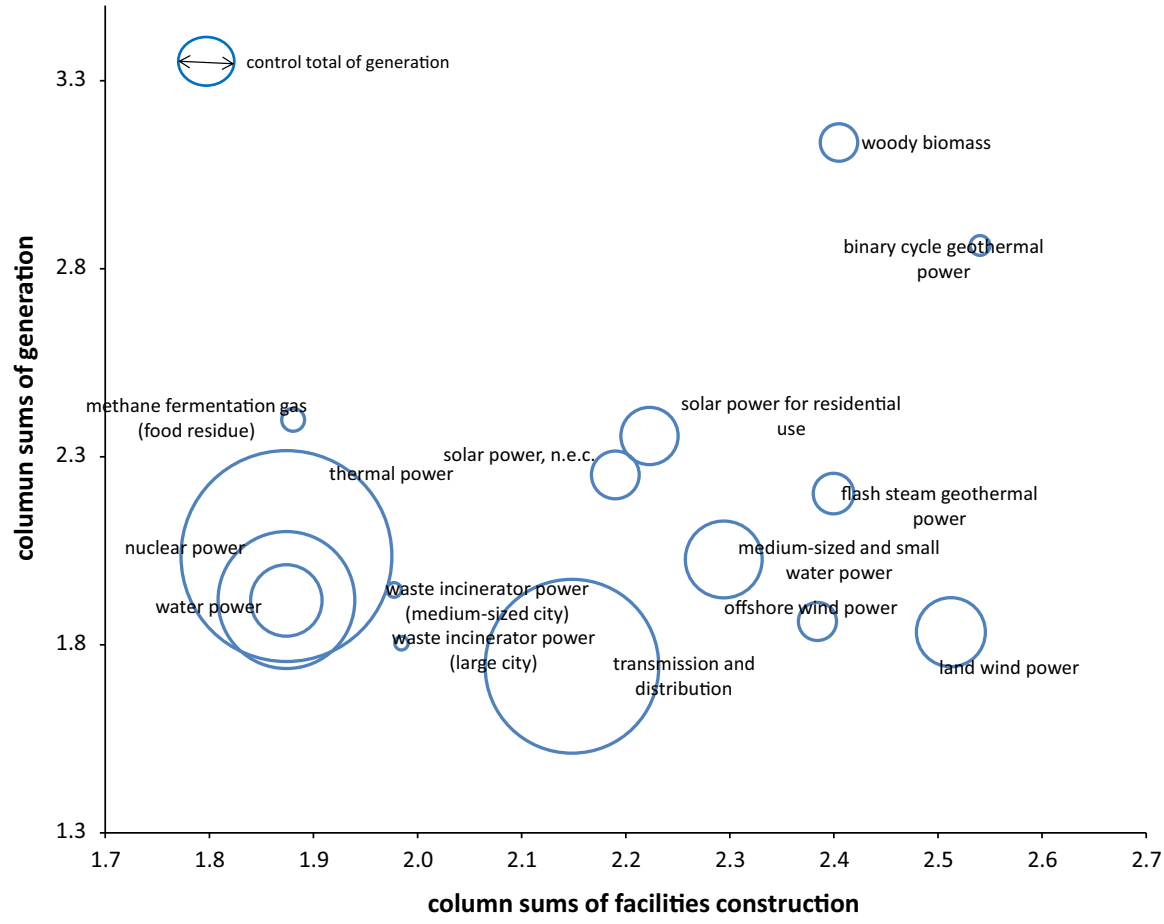

Fig. 1 Column sums of the Leontief inverse for renewable energy sectors 
$124 \times 124$ square matrix for the "Extended table for 2005 " and a $143 \times 143$ square matrix for the "Extended table for 2030," and $\hat{M}$ is the import coefficient matrix. Similarly, $\hat{M}$ is a $124 \times 124$ or $143 \times 143$ diagonal matrix, and its diagonal element is $\hat{m}_{i i}$. Here, $\hat{m}_{i i}=m_{i} / d_{i}$ is the ratio of imports (in millions of JPY), $m_{i}$, to the total domestic demand (in millions of JPY), $d_{j}$, and is called the import coefficient. The import and input coefficients are calculated using the extended inputoutput table.

\subsection{Dispersion power of the renewable energy sector in 2030}

The sum of each column in the Leontief inverse matrices $\left[(I-(I-M) A)^{-1}\right]$ displays the power of dispersion (i.e., the power of production inducement) across the whole economy for a particular sector. The vertical axis of Fig. 1 presents the sum for each renewable energy power generation sector in the "Extended table for 2030." The horizontal axis shows the sum for each renewable energy facility construction sector. In addition, the control total (CT) for each generation sector assumed in the "Extended table for 2030" is shown as the diameter of each circle. The CT of thermal power remains stubbornly large, suggesting the importance of thermal power as a back-up power source. The CT of transmission/distribution service is also large because it is an indispensable input for all power sectors. From Fig. 1, it is clear that the majority of renewable energy sources, in terms of both power generation and facilities construction activities, have a greater power of dispersion across the economy than do existing energy sources (nuclear, thermal, and hydro). The power of dispersion of woody biomass and binary cycle geothermal power is particularly large. The economic effect of constructing wind power plants is large, but its power of dispersion during generation is comparable to that of existing energy sources.

Note that methane fermentation gas (food residue), and a waste incinerator power work while disposing of waste, and flash steam geothermal power requires the construction of supplementary wells. Thus, the column sums for these generation sectors have been amended to include figures for waste disposal activities and for constructing supplementary wells for flash steam geothermal power, as shown in Fig. 1. After these adjustments, the power of dispersion from methane fermentation gas (food residue) and waste incinerator power as well as from constructing flash steam geothermal power increases significantly.

\subsection{Change in sensitivity/power of dispersion in each sector between 2005 and 2030}

The row sums and column sums of the Leontief inverse $\left[(I-(I-M) A)^{-1}\right]$ suggest the sensitivity of dispersion and the power of dispersion, respectively. The sectors with large row sums are those producing versatile goods and services, such as finance and insurance, business services, and petroleum refinery products. The sectors with large column sums are those producing highly processed goods and services, such as passenger motor cars and office supplies. The sensitivity of dispersion and the 
power of dispersion of motor vehicle parts and accessories and of steel products are both large. In the "Extended table for 2030," the transmission/distribution sector is fourth in terms of the sensitivity of dispersion. The majority of the newly established sectors rank high on the power of dispersion in the "Extended table for 2030."

While the total production of electricity in both the "Extended table for 2005" and the "Extended table for 2030" use actual 2005 data, the electricity supply structure is significantly different after including renewables. Comparing the two, the changes in the economic effects after introducing renewable energy are evident.

The vertical axis of Fig. 2 shows the changes in the row sums of the Leontief inverse $\left[(I-(I-M) A)^{-1}\right]$, namely, the sensitivity of dispersion, between the "Extended table for 2005" and the "Extended table for 2030." The sectors in which the figures increase are those supplying inputs required to construct or

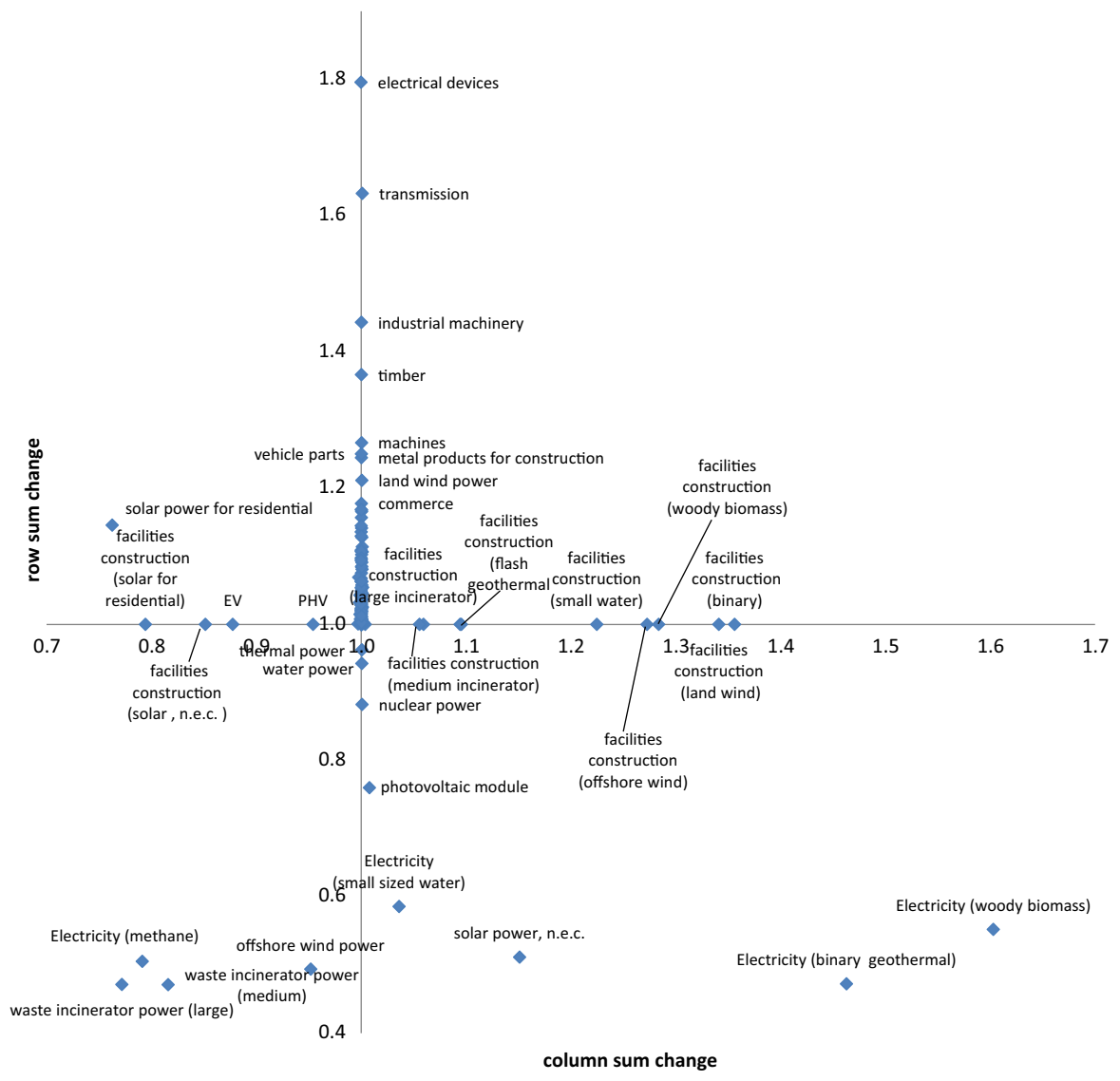

Fig. 2 Changes in row/column sums of the Leontief inverse from 2005 to 2030. For sectors related to renewable energies that did not exist in 2005, the figures represent the changes from the average of the electricity sectors that did exist in 2005. In addition, the electric and hybrid vehicle sector figures reflect the changes from the conventional gas vehicle sector 
operate renewable energy power plants. The figures for the transmission/distribution and business service sectors also increase, suggesting that the economic sensitivity of those sectors increases with the use of renewable energy. It is said that new types of transmission/distribution services (e.g., smart grid services) and business services (e.g., energy management services and telecommunication services) are needed to effectively manage small and distributed renewable energy grids. If these services are actually industrialized in the near future, the sensitivity of these sectors will increase significantly. The separation of transmission/distribution sectors from the conventional IO sectors is indispensable when calculating such effects.

Those sectors in which the figures decrease are electricity sectors and the photovoltaic module. It is likely that the photovoltaic module's row sum of the Leontief inverse in the "Extended table for 2030" will decrease because the input coefficient required in the industrial solar power facilities construction sector is comparatively low. The economic sensitivities of the renewable energy generation sectors are smaller than the average sensitivities of the electricity sectors that existed in 2005 .

The horizontal axis of Fig. 2 presents the changes in the column sums of the Leontief inverse $\left[(I-(I-M) A)^{-1}\right]$ between the "Extended table for 2005" and the "Extended table for 2030." While no large increases are visible in other sectors, there are significant changes in the renewable energy facility construction sector and the renewable energy generation sector. The column sums of the sectors that require large inputs, such as the facility construction of binary cycle geothermal power, wind power, and the power generation sector of woody biomass, increase. In 2005, the sale of solar energy had not yet been industrialized. Therefore, in the "Extended table for 2005," the sector of residential solar power electricity has no value-added, and its input coefficients and Leontief inverse coefficients are large. Hence, the sector has a small rate of change on the horizontal axis. Because the horizontal axis shows the rate of change in each sector's domestic induced effect, sectors that use more imported inputs than they did previously are located on the left-hand side of Fig. 2. Such is the case for both the residential and industrial solar power facility construction sectors. The import coefficient of the photovoltaic module, which is the major input required in the solar power facility construction sector, is assumed to increase significantly from 2005 to 2030. Electric and hybrid vehicles are also located on the left-hand side of Fig. 2 because electric and hybrid vehicles have fewer components than conventional gas vehicles and also because the input coefficient vector of the former is simpler than that of the latter.

\subsection{Changes in the production values induced by final demand from 2005 to 2030}

Table 1 shows the changes in the production values induced by 1 million JPY of each final demand component from the "Extended table for 2005" to the "Extended table for 2030," emphasizing the values related to energy sectors. In the "Extended table for 2030," the production value induced by 1 million JPY of total final demand falls by 355 JPY in the existing electricity (nuclear, thermal, and hydro power) facility construction sectors and by 6,124 JPY in the existing power generation 


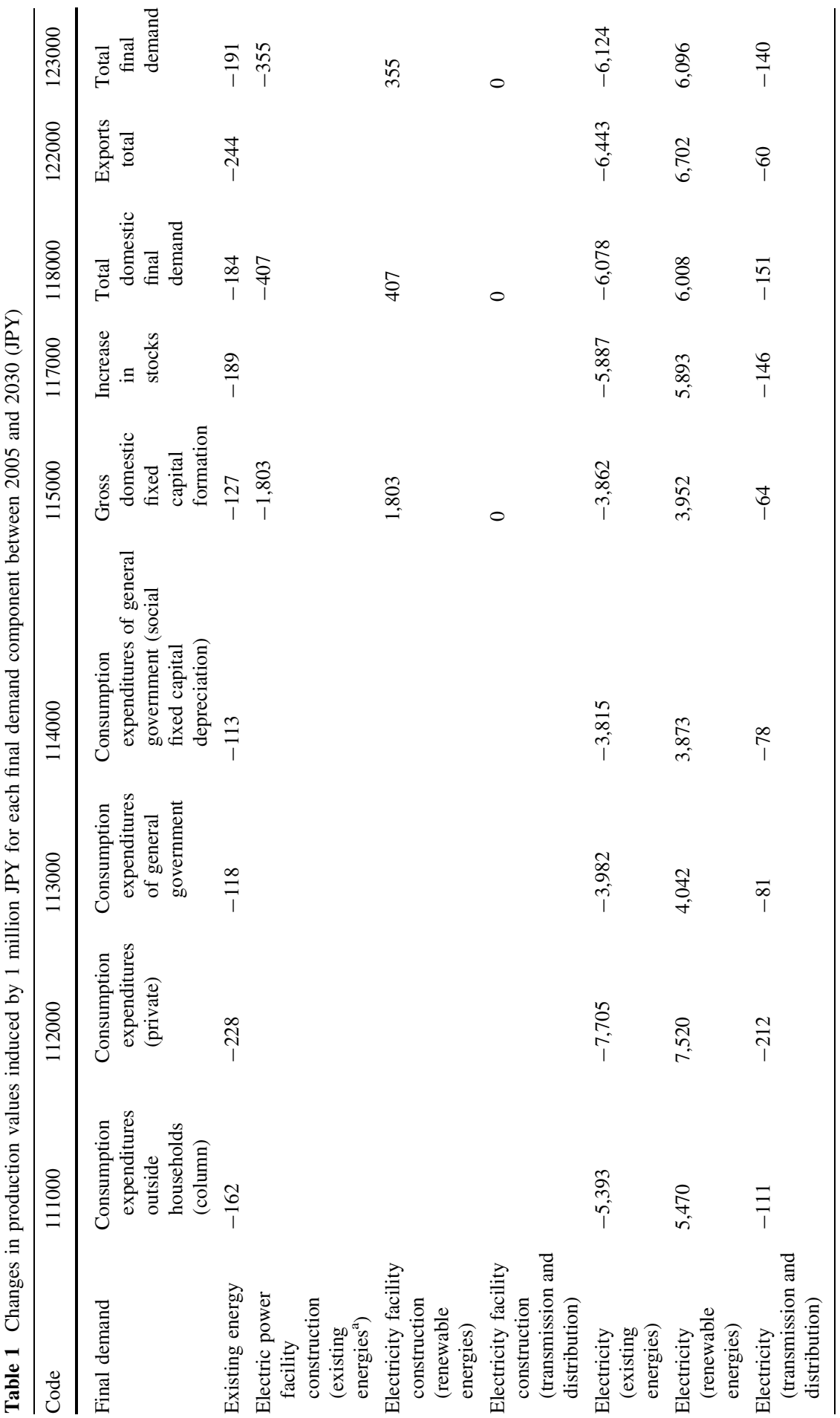




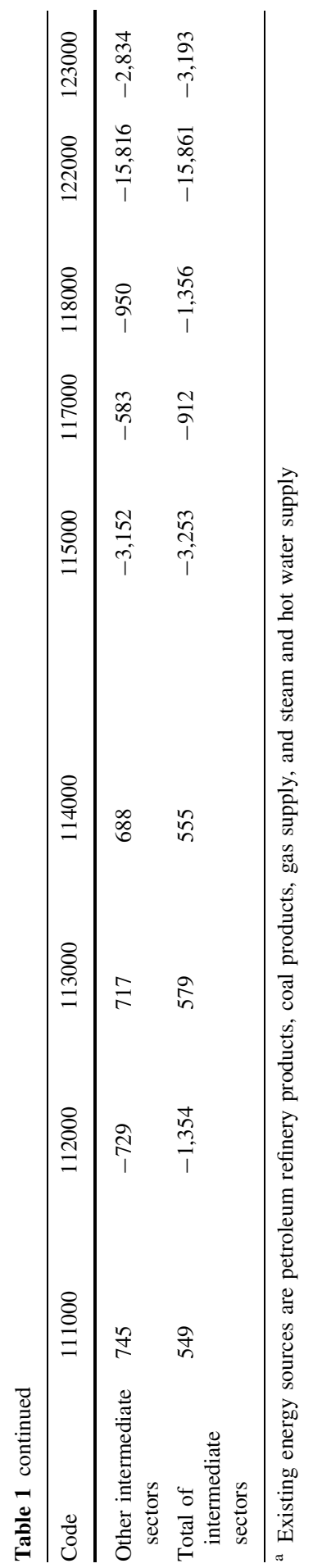


sectors from the values in the "Extended table for 2005." In contrast, the induced production value increases by 355 JPY in the renewable energy facilities construction sector and by 6,096 JPY in the renewable energy power generation sector, which almost offsets the reductions in the existing electricity facility construction and generation sectors. This change in inducement from 1 million JPY of household consumption expenditures is relatively large. The "Extended table for 2030" indicates that the utilization of renewable energy electricity expands across the economy, while that of conventional electricity contracts. Furthermore, in the "Extended table for 2030," the total induced production value induced by 1 million JPY of the total final demand falls by 3,193 JPY. For each item of final demand, the total inducements from 1 million JPY of total exports and of gross domestic fixed capital formation fall significantly, by 15,861 and 3,253 JPY, respectively. The aggregated share of chemical, metal, and machinery products (i.e., energy-intensive products) is $5.8 \%$ of household consumption expenditures but $28.9 \%$ of gross domestic fixed capital formation and $68.2 \%$ of total exports, respectively. This difference causes the difference in the change of production inducement from each final demand item. Thus, the production value induced by energy-intensive products decreases in a society using renewable energy.

Table 2 displays those sectors that experienced significant changes in production values induced by total final demand between the "Extended table for 2005" and the "Extended table for 2030." Here, the newly established sectors with no production in the "Extended table for 2005," such as the majority of the renewable energy power sectors and hybrid and electric vehicles, are excluded. The sectors in which the induced production values are greater in the "Extended table for 2030" include services, such as research, repairs, and business services, and primary products, such as timber and wooden products. Those sectors in which the induced production values in the "Extended table for 2030" decrease are those in which the demand switches to the newly established sectors (e.g., the demand for conventional passenger vehicles switches to hybrid or electric vehicles). In addition, the induced production value in energy-intensive industries, such as chemicals and ferrous and non-ferrous metals, declines.

\section{Analysis of the reduction in costs caused by the FIT system}

Previous studies that have analyzed the cost-push effects of increases in energy prices using input-output pricing models include Suzuki and Uchiyama (2010), Tarancon et al. (2010), Kerschner et al. (2013), Jiang and Tan (2013), and Gemechu et al. (2014). Suzuki and Uchiyama (2010) conduct a factor analysis of the effects of an increase in energy prices on the price of non-energy resources through the inputoutput relationship. Tarancon et al. (2010) and Kerschner et al. (2013) analyze how increases in various sectors' prices are caused by changes in electricity and oil prices (i.e., changes in the value-added ratios of electricity and oil). Jiang and Tan (2013) analyze the effect of changes in energy input prices resulting from reformed energy subsidies. Gemechu et al. (2014) analyze the price effects of changes in $\mathrm{CO}_{2}$ taxes and social security taxes using a model that incorporates tax rates for energy input coefficients and value-added components. 
Table 2 Changes in production values induced by final demand between 2005 and 2030 (million JPY)

\begin{tabular}{|c|c|c|c|c|c|}
\hline \multicolumn{2}{|c|}{$\begin{array}{l}\text { Top } 20 \text { sectors showing positive } \\
\text { movement }^{\mathrm{a}}\end{array}$} & \multirow{2}{*}{$\begin{array}{l}\begin{array}{l}\text { Degree } \\
\text { of } \\
\text { change }\end{array} \\
907,684\end{array}$} & \multicolumn{2}{|c|}{$\begin{array}{l}\text { Bottom } 20 \text { sectors showing } \\
\text { negative movement }\end{array}$} & \multirow{2}{*}{$\begin{array}{l}\begin{array}{l}\text { Degree of } \\
\text { change }\end{array} \\
-32,718\end{array}$} \\
\hline 051900 & Other electrical equipment, n.e.c. & & 027000 & $\begin{array}{l}\text { Final chemical } \\
\text { products, n.e.c. }\end{array}$ & \\
\hline 069221 & Electricity (land wind power) & 778,319 & 079000 & $\begin{array}{l}\text { Road transport (except } \\
\text { transport by private } \\
\text { cars) }\end{array}$ & $-35,844$ \\
\hline 069211 & $\begin{array}{l}\text { Electricity (solar power for } \\
\text { residential use) }\end{array}$ & 504,263 & 033000 & $\begin{array}{l}\text { Glass and glass } \\
\text { products }\end{array}$ & $-36,188$ \\
\hline 073000 & Commerce & 493,958 & 053000 & $\begin{array}{l}\text { Household electronics } \\
\text { equipment }\end{array}$ & $-52,703$ \\
\hline 093000 & Research & 351,056 & 042000 & $\begin{array}{l}\text { Non-ferrous metal } \\
\text { products }\end{array}$ & $-58,024$ \\
\hline 066000 & Repair of construction equipment & 248,855 & 039000 & $\begin{array}{l}\text { Cast and forged steel } \\
\text { products }\end{array}$ & $-75,115$ \\
\hline 069241 & $\begin{array}{l}\text { Electricity (flash steam } \\
\text { geothermal power) }\end{array}$ & 224,051 & 031000 & Rubber products & $-76,164$ \\
\hline 049000 & Electrical devices and parts & 210,696 & 069300 & $\begin{array}{l}\text { Electricity } \\
\text { (transmission and } \\
\text { distribution) }\end{array}$ & $-81,644$ \\
\hline 101000 & Other business services & 189,417 & 028000 & $\begin{array}{l}\text { Petroleum refinery } \\
\text { products }\end{array}$ & $-86,910$ \\
\hline 098000 & Advertising services & 157,861 & 068110 & $\begin{array}{l}\text { Electricity facility } \\
\text { construction (nuclear } \\
\text { power) }\end{array}$ & $-89,848$ \\
\hline 015000 & Timber and wooden products & 113,722 & 037000 & $\begin{array}{l}\text { Pig iron and crude } \\
\text { steel }\end{array}$ & $-109,425$ \\
\hline 090000 & $\begin{array}{l}\text { Image information, character } \\
\text { information production and } \\
\text { distribution }\end{array}$ & 62,138 & 068120 & $\begin{array}{l}\text { Electricity facility } \\
\text { construction } \\
\text { (thermal power) }\end{array}$ & $-120,003$ \\
\hline 019000 & $\begin{array}{l}\text { Printing, plate making and book } \\
\text { binding }\end{array}$ & 51,402 & 030000 & Plastic products & $-141,201$ \\
\hline 055000 & $\begin{array}{l}\text { Semiconductor devices and } \\
\text { integrated circuits }\end{array}$ & 50,430 & 051110 & $\begin{array}{l}\text { Photovoltaic module } \\
\text { (polycrystalline } \\
\text { silicon) }\end{array}$ & $-157,634$ \\
\hline 086000 & Communication & 42,843 & 038000 & Steel products & $-182,961$ \\
\hline 075000 & $\begin{array}{l}\text { Real estate agencies and rental } \\
\text { services }\end{array}$ & 41,401 & 069130 & $\begin{array}{l}\text { Electricity (water } \\
\text { power) }\end{array}$ & $-442,561$ \\
\hline 087000 & Broadcasting & 40,367 & 069110 & $\begin{array}{l}\text { Electricity (nuclear } \\
\text { power) }\end{array}$ & $-1,499,414$ \\
\hline 088000 & Information services & 37,584 & 069120 & $\begin{array}{l}\text { Electricity (thermal } \\
\text { power) }\end{array}$ & $-1,594,733$ \\
\hline 080000 & Self-transport by private cars & 36,812 & 059000 & $\begin{array}{l}\text { Motor vehicle parts } \\
\text { and accessories }\end{array}$ & $-3,866,032$ \\
\hline 068212 & $\begin{array}{l}\text { Electric power facilities } \\
\text { construction (solar power, } \\
\text { n.e.c.) }\end{array}$ & 32,571 & 057100 & $\begin{array}{l}\text { Passenger motor cars, } \\
\text { n.e.c. }\end{array}$ & $-8,690,471$ \\
\hline
\end{tabular}

\footnotetext{
a Newly established sectors with no production in the "Extended table for 2005," such as the majority of the renewable energy power sectors and hybrid or electric vehicles, are excluded
} 
This study, by establishing the deduction (row) vector of the FIT as a valueadded item in the "Extended table for 2030," describes the FIT as a current subsidy. Therefore, should the subsidy be removed and the cost of the value-added increase, the percentage increase in costs for each sector can then be calculated using the following formula:

$$
p=\left(I-A^{\prime}\right)^{-1} \text { fit }
$$

where fit is a vector in which the elements are the FITs per production of renewable energy power generation. The main results are presented in Figs. 3 and 4. The 11 sectors with the greatest increases in price ratios are all renewable energy sectors, and the price increase ratio for solar power electricity for residential use is particularly large (see Fig. 3). In addition, a significant increase in price ratios is shown in the existing power sectors, such as steam and hot water supply and thermal power electricity, in non-ferrous metals, and in heavy and chemical industries, such as pig iron and crude steel (see Fig. 4). When the percentage price increases in each sector are multiplied by the domestic output in the "Extended table for 2030," the total is 10.7 trillion JPY, which represents the total benefit of the FIT after reducing renewable energy power prices by suppressing overall price increases.

Moreover, while the FIT totaled 3.9 trillion JPY, this figure can be perceived as being levied on the consumer. In the absence of this system, it is possible that this money would be left in the hands of consumers, thus increasing the domestic final demand by that amount. The induced effect of an increase in the domestic final demand of 3.9 trillion JPY on the entire economy is as follows:

$$
x_{\mathrm{FDfit}}=(I-(I-\hat{M}) A)^{-1}(I-\hat{M}) \mathrm{FD}_{\mathrm{fit}}
$$

where $\mathrm{FD}_{\text {fit }}$ is the vector that results from 3.9 trillion JPY being divided by the column distribution components of the domestic final demand vector.

As a result, the 3.9 trillion JPY of domestic final demand induces 6.3 trillion JPY of production, which is the economic effect of not having a FIT. This total can be viewed as the opportunity cost of the system. Consequently, the net effect is approximately 4.4 trillion JPY after subtracting the opportunity cost from the

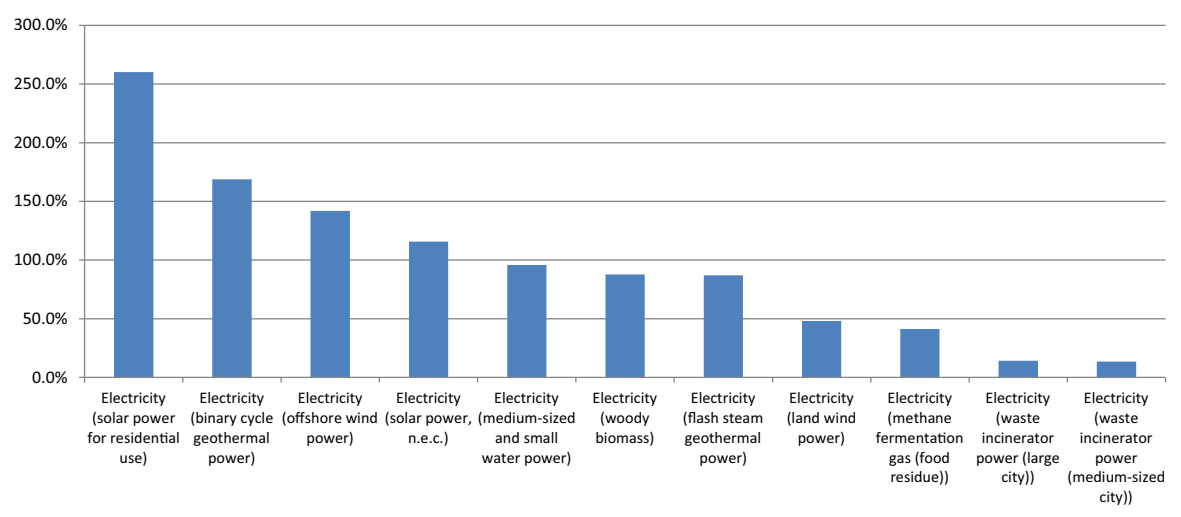

Fig. 3 Percentage price increases when the FIT is removed: Top 11 sectors 


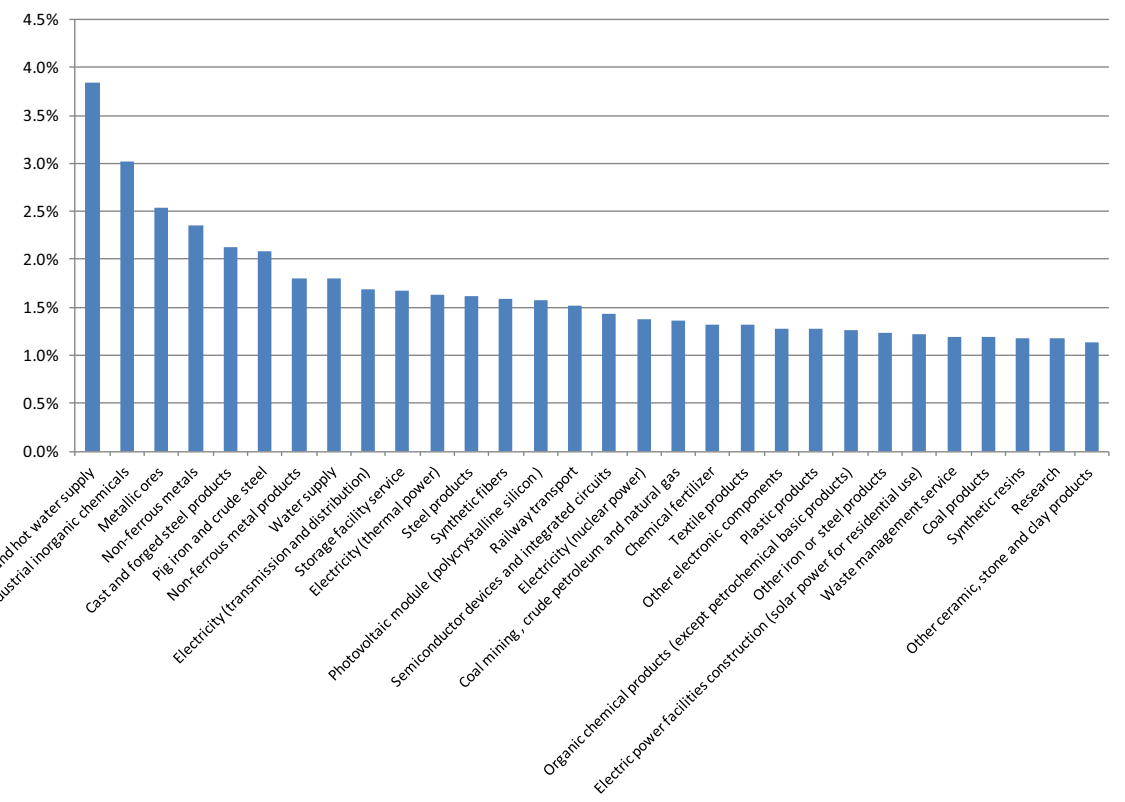

Fig. 4 Percentage price increases when the FIT is removed: Sectors 12 through 41

benefits of the FIT system (10.7 trillion JPY minus 6.3 trillion JPY). Table 3 shows the 20 sectors with the largest net effect and the 20 with the smallest net effect. In addition to the renewable energy power sectors, the other sectors with the largest net effects include iron and steel, non-ferrous metals, electronic components, and thermal power electricity. Those with the smallest net effects include the service sector for individuals and businesses, agriculture, foodstuffs, and construction.

\section{Conclusion}

In Japan, amidst discussions over the FIT system and utility grid reforms, increasing attention has been paid to the effects of separating electricity transmission/distribution and generation and the introduction of renewable energy on the environment and the economy. Because energy requires a fundamental investment in the economy, energy issues represent relevant analytical issues in input-output analyses. Therefore, in this study, we created an input-output table to analyze the next-generation energy system as a basis for such analyses.

These tables were used to calculate Leontief inverse coefficients to compare the induced effect for the overall economy of power generation and facility construction for various renewable energy sources. The majority of renewable energy sources, in both power generation and facility construction activities, have a greater induced effect on the overall economy than do existing power sources (nuclear, thermal, and 
Table 3 Net effects of the FIT system

\begin{tabular}{|c|c|c|c|c|}
\hline Code & Sector & $\begin{array}{l}\text { A } \\
\text { Benefit }\end{array}$ & $\begin{array}{l}\text { B Opportunity } \\
\text { cost }\end{array}$ & $\begin{array}{l}\text { A-B Net } \\
\text { effect }\end{array}$ \\
\hline \multicolumn{5}{|c|}{ The top 20 sectors showing positive net effects } \\
\hline 069211 & Electricity (solar power for residential use) & $1,388,013$ & 3,609 & $1,384,404$ \\
\hline 069230 & Electricity (medium-sized and small water power) & 918,643 & 6,490 & 912,152 \\
\hline 069212 & Electricity (solar power, n.e.c.) & 431,274 & 2,520 & 428,754 \\
\hline 069221 & Electricity (land wind power) & 373,251 & 5,235 & 368,016 \\
\hline 069222 & Electricity (offshore wind power) & 332,243 & 1,584 & 330,659 \\
\hline 069241 & Electricity (flash steam geothermal power) & 234,044 & 1,820 & 232,225 \\
\hline 059000 & Motor vehicle parts and accessories & 313,230 & 82,485 & 230,746 \\
\hline 069251 & Electricity (woody biomass) & 200,465 & 1,546 & 198,919 \\
\hline 038000 & Steel products & 223,239 & 56,359 & 166,880 \\
\hline 037000 & Pig iron and crude steel & 158,330 & 28,828 & 129,503 \\
\hline 069242 & Electricity (binary cycle geothermal power) & 108,058 & 433 & 107,625 \\
\hline 056000 & Other electronic components & 140,491 & 33,792 & 106,699 \\
\hline 093000 & Research & 154,364 & 68,095 & 86,269 \\
\hline 030000 & Plastic products & 135,436 & 53,561 & 81,875 \\
\hline 042000 & Non-ferrous metal products & 93,096 & 22,411 & 70,685 \\
\hline 069120 & Electricity (thermal power) & 118,179 & 48,846 & 69,333 \\
\hline 055000 & Semiconductor devices and integrated circuits & 74,730 & 6,874 & 67,856 \\
\hline 023000 & $\begin{array}{l}\text { Organic chemical products (except petrochemical } \\
\text { basic products) }\end{array}$ & 68,996 & 16,685 & 52,311 \\
\hline 078000 & Railway transport & 99,188 & 47,451 & 51,736 \\
\hline 028000 & Petroleum refinery products & 147,596 & 96,268 & 51,328 \\
\hline \multicolumn{5}{|c|}{ The bottom 20 sectors showing negative net effects } \\
\hline 001000 & Crop cultivation & 29,512 & 48,602 & $-19,090$ \\
\hline 106000 & Other personal services & 42,886 & 62,734 & $-19,848$ \\
\hline 090000 & $\begin{array}{l}\text { Image information, character information } \\
\text { production and distribution }\end{array}$ & 29,687 & 50,339 & $-20,652$ \\
\hline 098000 & Advertising services & 36,893 & 59,772 & $-22,879$ \\
\hline 096000 & Nursing care & 25,854 & 49,891 & $-24,037$ \\
\hline 097000 & Other public services & 13,349 & 37,855 & $-24,506$ \\
\hline 067000 & Public construction & 84,332 & 126,580 & $-42,248$ \\
\hline 079000 & Road transport (except transport by private cars) & 62,026 & 113,366 & $-51,341$ \\
\hline 099000 & Goods rental and leasing services & 25,627 & 79,474 & $-53,847$ \\
\hline 086000 & Communication & 63,237 & 118,656 & $-55,419$ \\
\hline 088000 & Information services & 58,574 & 125,629 & $-67,055$ \\
\hline 076000 & House rent & 12,033 & 93,043 & $-81,011$ \\
\hline 092000 & Education & 95,678 & 179,885 & $-84,206$ \\
\hline 094000 & Medical service and health & 204,949 & 290,600 & $-85,651$ \\
\hline 065000 & Building construction & 143,461 & 239,908 & $-96,446$ \\
\hline 091000 & Public administration & 180,248 & 299,669 & $-119,421$ \\
\hline 101000 & Other business services & 56,780 & 206,059 & $-149,278$ \\
\hline
\end{tabular}


Table 3 continued

\begin{tabular}{llrll}
\hline Code & Sector & $\begin{array}{l}\text { A } \\
\text { Benefit }\end{array}$ & $\begin{array}{l}\text { B Opportunity } \\
\text { cost }\end{array}$ & $\begin{array}{l}\text { A-B Net } \\
\text { effect }\end{array}$ \\
\hline 073000 & Commerce & 560,790 & 712,178 & $-151,388$ \\
074000 & Finance and insurance & 88,780 & 287,938 & $-199,158$ \\
077000 & House rent (imputed house rent) & 19,043 & 356,782 & $-337,740$ \\
\hline
\end{tabular}

hydro). The effect for woody biomass and binary cycle geothermal power is particularly large, and while the induced effect of setting up wind power facilities is large, the effect when generating power is similar to that of existing power sources (see Fig. 1).

Comparing the results from the "Extended table for 2005" with those from the "Extended table for 2030" enables us to estimate the effects of introducing renewable energy into the same economic structure. All production values for existing energy, existing electric power facility construction, and existing electricity generation induced by the final demand shown in the "Extended table for 2030" are diminished when compared with the "Extended table for 2005." Conversely, induced production values for renewable energy power facility construction and renewable energy power generation showed an enormous increase (see Table 1). The "Extended table for 2030" clearly shows a situation in which the use of renewable energy sources extends across the economy, while the use of existing energy sources is curtailed. In addition, manufacturing production in existing sectors (existing power generation, existing passenger vehicles) induced by final demand was reduced and replaced by the new sectors (EVs, PHVs, and renewable energy sectors), which also reduced the demand for production in the supply chain of these existing sectors (i.e., energyintensive sectors, such as chemical industries and iron and non-ferrous metals). Moreover, we demonstrated that after introducing renewable energies, there are large increases in induced production in service sectors, such as research and business services, and in primary sectors, such as lumber and wood products (see Table 2).

Our analysis considers FITs for the production of renewable energy as subsidies and subtracts the subsidy value from the value-added. Here, we used a Leontief value model to analyze the effect of these subsidies on the economy. If the subsidy is removed and the cost of value-added increases, the percentage increases in the prices in the renewable energy sector (particularly solar power for residential use) are steep (see Fig. 3). In addition, costs increased significantly in the existing energy sectors, such as steam and hot water supply and thermal power electricity, and in heavy and chemical industries, such as non-ferrous metals, pig iron, and crude steel (see Fig. 4). When the percentage price increases in each sector are multiplied by the corresponding domestic output in the "Extended table for 2030," the total is 10.7 trillion JPY. This amount can be viewed as the benefit of the FIT (i.e., the effect of restricting increases in prices). 
However, because the costs of the FIT system are largely borne by consumers, if this money is left in the hands of those consumers, it is possible that final demand would increase by that amount. If so, the result is 6.3 trillion JPY of induced production through domestic final demand. Because this amount represents the economic effect of removing the FIT system, it is the system's opportunity cost. The net effect after subtracting this opportunity cost from the benefit of the FIT system is approximately 4.4 trillion JPY. In addition to renewable energy, sectors in which this net effect is the largest include iron and steel, non-ferrous metals, electronic components, and thermal power plants. The sectors in which the effect is the smallest include the service sectors for individuals and businesses, agriculture, foodstuffs, and construction (see Table 3).

While the benefit of the FIT is large in the renewable energy sectors, it is also clear that the benefit is large in heavy and chemical industries. In the latter case, induced production is reduced with the use of renewable energy. However, the benefit is relatively small in the service sector, in which induced production increases (compare Tables 5 and 6). This result is rather paradoxical, but it occurs because the positive effect of the FIT system is larger than the negative effect in the heavy and chemical industries, while the negative effect is larger in the service sectors, on which the cost of the FIT system is levied. Thus, the FIT system appears to benefit the overall Japanese economy, but the benefits are not divided equally among the sectors. However, because renewable-energy-induced service activities such as research and business services are becoming more pervasive, this inequality may be resolved in the long term and could be assisted by policies that accelerate this change.

In Japan, since the introduction of the FIT, only the introduction of solar energy has developed rapidly. As a result, given the fluctuations in the output of solar power generation, the stable supply of electric power has come to be recognized as an important technical issue by electricity providers. Therefore, the focus is now on a smart grid as one means of resolving this technical problem. A smart grid increases the flexibility of the utility grid and increases the extent to which fluctuations in the supply of solar and wind power can be managed, thereby making the efficient use of small-scale, dispersed renewable energy power possible. However, there are many choices in constructing a smart grid, and each brings with it an infrastructure investment. Because Japan's current energy infrastructure has rigid restrictions in terms of the availability of renewable energy, caution on this point is essential. Furthermore, engineers predict that future smart grid systems will introduce new services to the economy, such as new types of information services, security services, and energy management services. This situation is also likely to occur in other Asian countries, as severe environmental problems will force them to alter their energy composition.

In future research using our extended input-output tables, we will analyze the economic effects of alternative ways to construct a smart grid and identify a desirable modern energy system. The analytical method developed for the Japanese economy will then be applied to other Asian countries, as almost all Asian governments produce their own input-output tables. 
Acknowledgments This study incorporates research undertaken as part of a MEXT Grant-in-Aid for Scientific Research (Category B. Project number 23310033. Lead researcher: WASHIZU Ayu), 2011-2014, and a Waseda University Grant for Special Research Projects (Project number: 2015A-065).

Open Access This article is distributed under the terms of the Creative Commons Attribution 4.0 International License (http://creativecommons.org/licenses/by/4.0/), which permits unrestricted use, distribution, and reproduction in any medium, provided you give appropriate credit to the original author(s) and the source, provide a link to the Creative Commons license, and indicate if changes were made.

\section{Appendix: Details on the construction of the extended input-output tables}

\section{Estimating the production volume (control total) of each electricity sector}

\section{"I. The Electrical transmission/distribution sectors for 2005"}

The following documents are used to capture the control total data for the transmission/distribution sector given in "I. The Electrical transmission/distribution sectors for $2005 "$ :

1. Itemized accounts of operating expenses from 10 power and electricity companies

2. Itemized accounts for developing and managing power plants

3. Profit and loss statements from regional public enterprises.

\section{“II. Extended renewable energy sectors for 2005” ("Extended table for 2005”)}

The actual data for renewable energy power generation used in "II. Extended renewable energy sectors for 2005" ("Extended table for 2005") are those provided by the 2005 power company handbook. This handbook provides figures for geothermal, solar, and wind electricity generation for self-consumption.

\section{“III. Extended renewable energy sectors for 2030” ("Extended table for 2030”)}

In the table "III. Extended renewable energy sectors for 2030" ("Extended table for 2030"), we divide activities related to power facility construction and power generation into the 14 sectors presented in Table 4 . The passenger vehicles sector is divided into three types, as shown in Table 5. The reason for disaggregating the activities for electric vehicles from the original sector is that, in the future, together with the dissemination of solar power (for residential use), it is anticipated that the batteries of such vehicles will help to moderate solar power variation and will also provide back-up. In the "Extended table for 2030," the actual 2005 cost of power facility construction is divided proportionately among the construction activities 


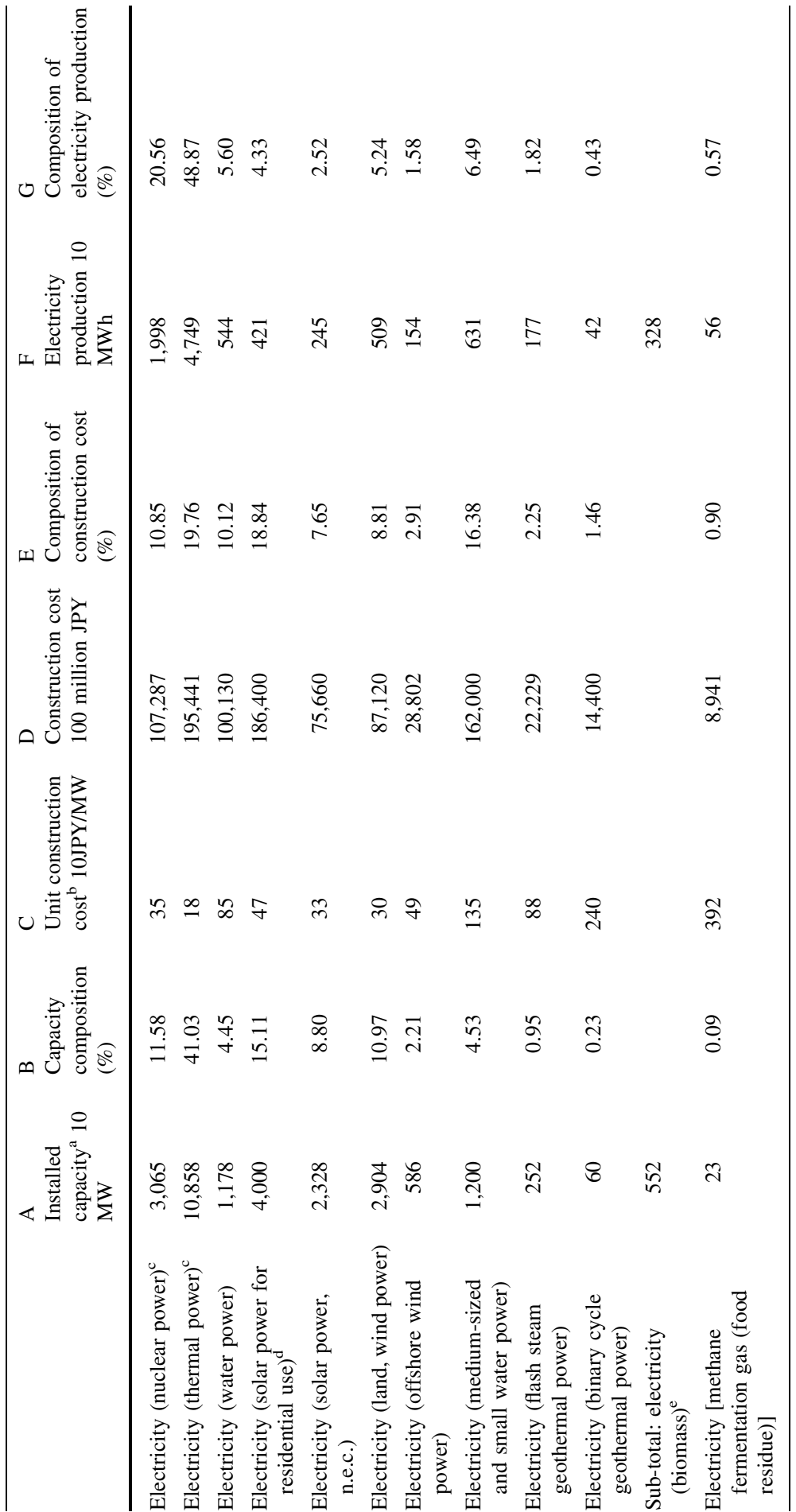




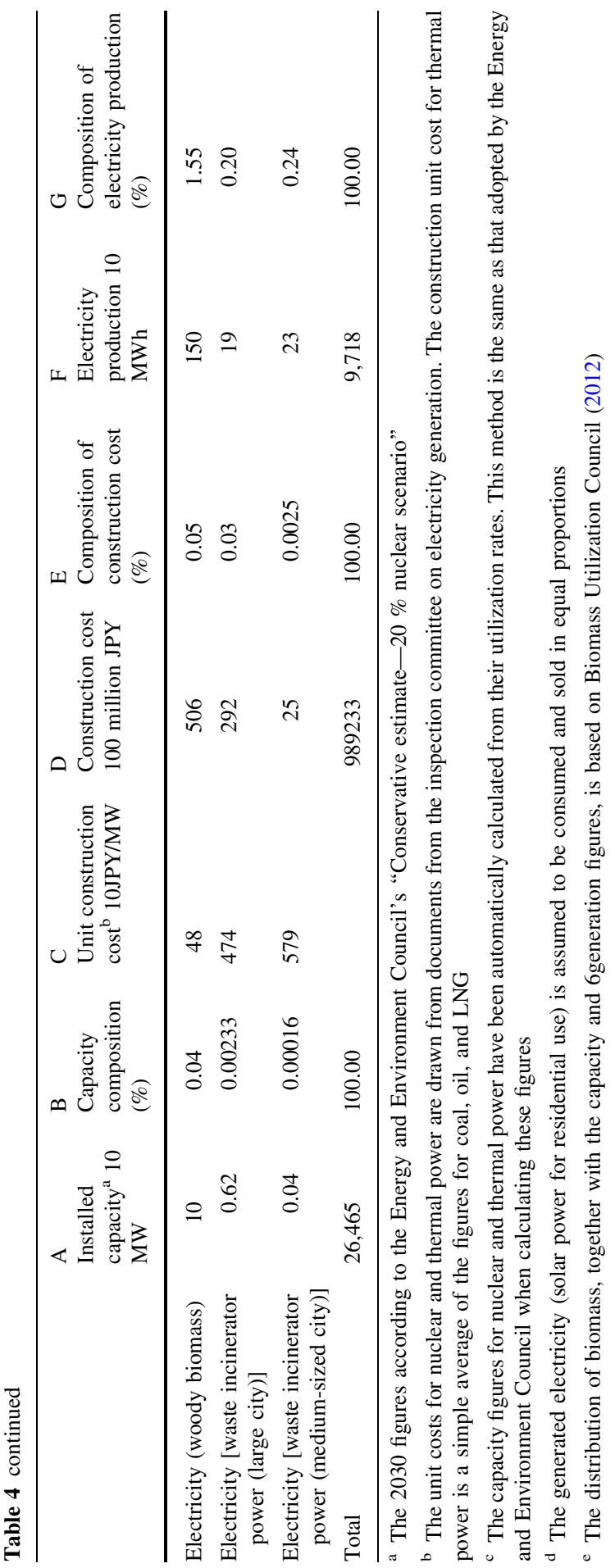


Table 5 Predicted 2030 passenger car production ratios

\begin{tabular}{llll}
\hline & $\begin{array}{l}\text { A } \\
\text { Composition of } \\
\text { cars (\%) }\end{array}$ & $\begin{array}{l}\text { B } \\
\text { Assumed price }(10 \\
\text { thousand JPY) }\end{array}$ & $\begin{array}{l}\text { Cominal } \\
\text { composition (\%) }\end{array}$ \\
\hline $\begin{array}{l}\text { Passenger motor cars, n.e.c. } \\
\begin{array}{l}\text { Passenger motor cars (hybrid } \\
\text { vehicles) }\end{array}\end{array}$ & 52 & 180 & 40.56 \\
$\begin{array}{l}\text { Passenger motor cars (electric } \\
\text { vehicles) }\end{array}$ & 19 & 241 & 30.29 \\
\hline
\end{tabular}

shown in column "E" of Table 4. In addition, the actual 2005 power generation figures are divided proportionately among the various power sectors in column " $\mathrm{G}$ " of Table 4. Table 4 is based on the "Documents on renewable energy," which is produced by the Energy and Environment Council. The control total for passenger cars in 2005 is divided proportionately among the three types of passenger vehicles in column " $\mathrm{C}$ " of Table 5. The proportions in Table 5 are based on the "Documents on energy saving" (Energy and Environment Council 2012a) produced by the Energy and Environment Council.

As a result of the need to renew the wells in steam geothermal power plants, a separate section for "Electric power facility construction (supplementary wells for flash steam geothermal power)" is identified from general construction costs. "Electricity [methane fermentation gas (food residue)]" and "Electricity [waste incinerator power (large- and medium-sized city)]" are treated as separate sections of the waste management service. It is vital that these generation activities are analyzed in conjunction with the service activities. That is, if we estimate the electricity generation of these sectors, we must also predict their waste management service.

In the "Extended table for 2030," total demand for each input differs from the actual supply figures from 2005 because the input structures of the renewable energy sectors are much different from the electricity sectors that existed in 2005. Thus, within the "Extended table for 2030" is a "Balancing sector" to balance the difference from the actual figures. Note that the Leontief inverse table is calculated without the "Balancing sector."

\section{Estimating input coefficients in the extended tables}

The input coefficients for renewable energy facility construction and renewable energy power generation are estimated in the following manner.

For solar, wind, small- and medium-hydro, geothermal, and woody biomass generation:

a. A model power plant is assumed based on information provided by the inspection committee on electricity generation. 
b. The total investment and operational costs of the model plant are assumed based on the assumptions of the committee.

c. The total investment and operational costs are divided into individual inputs based on the information in Table 6 .

d. General management costs are divided into individual inputs according to proportion of inputs used by the head office of the electricity sector.

For methane fermentation gas and waste incinerators:

a. The waste incinerated per day by the model plant is set according to interviews with the related bodies.

b. The total investment and operational costs are calculated using Matsuto's (2005) optimized model, assuming point a.

c. The total investment and operational costs in point $b$ are divided into the activities of waste disposal and electricity generation based on the optimized results of Matsuto's (2005) model.

d. The division of the total investment and operational costs for each activity in point $\mathrm{c}$ among the input sectors refers to the input composition of the corresponding activity in the published input-output table.

The input coefficients for hybrid vehicles and electric vehicles are calculated by adjusting the published input coefficients for passenger vehicles using the information in Table 6 .

Table 6 Primary material used to estimate the input coefficients of the renewable energy sectors

\begin{tabular}{|c|c|}
\hline Solar power & $\begin{array}{l}\text { (NEDO) (2008), JPEA (2012), Mizuho Information \& Research } \\
\text { Institute (2009) }\end{array}$ \\
\hline Wind power & Interviews with JWPA, EWEA (2007) \\
\hline $\begin{array}{l}\text { Medium and small water } \\
\text { power }\end{array}$ & NEF (2009), ANRE and NEF (2013) \\
\hline Flash steam geothermal power & $\begin{array}{l}\text { Adachi (2011, 2012), NEDO and NEF (2002), MOE (2011), Hienuki } \\
\text { and Hondo }(2012,2013)\end{array}$ \\
\hline $\begin{array}{l}\text { Binary cycle geothermal } \\
\text { power }\end{array}$ & (MOE) (2011), Niigata Pref. (2010) \\
\hline Waste power & Interviews with business operators, Matsuto (2005) \\
\hline Woody biomass & Interviews with business operators \\
\hline $\begin{array}{l}\text { Methane fermentation gas } \\
\text { (food residue) }\end{array}$ & Tanaka and Matsuto (1998), Matsuto (2005) \\
\hline $\begin{array}{l}\text { Hybrid vehicle and electric } \\
\text { vehicles }\end{array}$ & $\begin{array}{l}\text { METI's Material Processing Technology Commission (2010), Kimura } \\
\text { (2013), Japan Auto Parts Industries Association (2007), Fuji Keizai } \\
\text { (2011) }\end{array}$ \\
\hline
\end{tabular}




\section{References}

Acquaye AA, Wiedmann T, Feng K, Crawford RH, Barrett J, Kuylenstierna J, Duffy AP, Koh SCL, McQueen-Mason S (2011) Identification of "carbon hot-spots" and quantification of GHG intensities in the biodiesel supply chain using hybrid LCA and structural path analysis. Environ Sci Technol 45:2471-2478. doi:10.1021/es103410q

Adachi M (2011) Study of economic efficiency of geothermal power generation projects. In: Stream and development technology of geothermal power generation. S\&T Publishing Inc., p 29-57. (In Japanese)

Adachi M (2012) Demand for geothermal electricity pricing. The Third MEXT Committee on Calculating Costs of Supply, March 19, 2012. http://www.meti.go.jp/committee/chotatsu_kakaku/003_07_00. pdf. Accessed 24 June 2015. (In Japanese)

Agency for Natural Resources and Energy (ANRE) (2013) Guidebook for feed-in tariffs in renewable energy. http://www.enecho.meti.go.jp/category/saving_and_new/saiene/data/kaitori/kaitori_ jigyousha2013.pdf. Accessed 24 June 2015. (In Japanese)

Agency for Natural Resources and Energy (ANRE), New Energy Foundation (NEF) (2013) Guide to integration construction costs in plans for hydroelectric Power Plants. http://www.enecho.meti.go.jp/ category/electricity_and_gas/electric/hydroelectric/download/pdf/ctelhy_011.pdf. Accessed 24 June 2015. (In Japanese)

Biomass Utilization Council (2012) The current state of and the issues regarding biomass utilization. http://www.maff.go.jp/j/biomass/suisinkaigi/04/pdf/siryo1.pdf. Accessed 24 June 2015. (In Japanese)

Bright RM, Strømman AH (2010) Fuel-mix, fuel efficiency, and transport demand affect prospects for biofuels in northern Europe. Environ Sci Technol 44:2261-2269. doi:10.1021/es903135c

Cai W, Wang C, Chen J, Wang S (2011) Green economy and green jobs: myth or reality? The case of China's power generation sector. Energy 36:5994-6003. doi:10.1016/j.energy.2011.08.016

Cai W, Mu Y, Wang C, Chen J (2014) Distributional employment impacts of renewable and new energy: a case study of China. Renewable Sustain Energ Rev 39:1155-1163. doi:10.1016/j.rser.2014.07.136

Caldés N, Varela M, Santamarıa M, Sáez R (2009) Economic impact of solar thermal electricity deployment in Spain. Energ Policy 37:1628-1636. doi:10.1016/j.enpol.2008.12.022

Crawford RH (2009) Life cycle energy and greenhouse emissions analysis of wind turbines and the effect of Size on energy yield. Renewable Sustain Energ Rev 13:2653-2660. doi:10.1016/j.rser.2009.07. 008

De Arce R, Mahıa R, Medina E, Escribano G (2012) A simulation of the economic impact of renewable energy development in Morocco. Energ Policy 46:335-345. doi:10.1016/j.enpol.2012.03.068

Energy and Environment Council (2012) Documents on energy saving. http://www.cas.go.jp/jp/seisaku/ npu/policy09/sentakushi/database/saiseikanou_kanrenshiryou.pdf. Accessed 24 Jan 2015. (In Japanese)

Energy and Environment Council (2012) Information on renewable energy. http://www.cas.go.jp/jp/ seisaku/npu/policy09/sentakushi/database/shouene_kanrenshiryou.pdf. Accessed 24 June 2015. (In Japanese)

European Wind Energy Association (2007) Wind directions. January/February 2007

Fuji Keizai (2011) Complete survey and analysis of the HEV and EV market, 2010 edn. (In Japanese)

Gemechu ED, Butnar I, Llop M, Castells F (2014) Economic and environmental effects of $\mathrm{CO}_{2}$ taxation: an input-output analysis for Spain. J Environ Plan Manag 57:751-768. doi:10.1080/09640568.2013. 767782

Guo J, Zou L, Wei Y (2010) Impact of inter-sectoral trade on national and global $\mathrm{CO}_{2}$ emissions: an empirical analysis of China and US. Energ Policy 38:1389-1397. doi:10.1016/j.enpol.2009.11.020

Hienuki S, Hondo H (2012) Analysis of the employment lifecycle of geothermal power generation using an extended input-output table The 28th Collection of Conference Papers on Energy Systems, Economy and Environment. (In Japanese)

Hienuki S, Hondo H (2013) Employment life cycle analysis of geothermal power generation using an extended input-output model. J Jpn Inst Energy 92:164-173. doi:10.3775/jie.92.164 (In Japanese)

Institute for Economic Analysis of Next-generation Science and Technology (2015) Input-output table for analysis of next-generation energy system. http://www.f.waseda.jp/washizu/table.html. Accessed 24 June 2015 
Ishikawa Y, Nakamura R, Matsumoto A (2014) Economic effects of installing renewable energy in the Tohoku region: analyses of mega solar and wind power generation using the interregional IO table. RIETI Policy Discussion Paper Series 12-P-014

Japan Auto Parts Industries Association (2007) 2005 Study on trends in shipping automobile components. (In Japanese)

Japan Photovoltaic Energy Association (JPEA) (2012). http://www.jpea.gr.jp/j-pec/data/. Accessed: 01 Feb 2013. (In Japanese)

Jiang Z, Tan J (2013) How the removal of energy subsidy affects general price in China: a study based on input-output model. Energ Policy 63:599-606. doi:10.1016/j.enpol.2013.08.059

Kerschner C, Prell C, Feng K, Hubacek K (2013) Economic vulnerability to peak oil. Glob Environ Change 23:1424-1433. doi:10.1016/j.gloenvcha.2013.08.015

Kimura S (2013) Chubu research quarterly: the Effect of the spread of next-generation automobiles on their manufacture in the Chubu Region, vol 7. Chubu Regional Research, 182. Chubu Region Institute for Social and Economic Research, p 33-51. (In Japanese)

Lambert RJ, Silva PP (2012) The challenges of determining the employment effects of renewable energy. Renewable Sustain Energ Rev 16:4667-4674. doi:10.1016/j.rser.2012.03.072

Lehr U, Nitsch J, Kratzat M, Lutz C, Edler D (2008) Renewable energy and employment in Germany. Energ Policy 36:108-117. doi:10.1016/j.enpol.2007.09.004

Lenzen M (2011) Aggregation versus disaggregation in input-output analysis of the environment. Econ Syst Res 23:73-89. doi:10.1080/09535314.2010.548793

Lindner S, Legault J, Guan D (2013) Disaggregating the electricity sector of China's input-output table for improved environmental life-cycle assessment. Econ Syst Res 25:300-320. doi:10.1080/ 09535314.2012 .746646

Madlener R, Koller M (2007) Economic and $\mathrm{CO}_{2}$ mitigation impacts of promoting biomass heating systems: an input-output study for Vorarlberg, Austria. Energ Policy 35:6021-6035. doi:10.1016/j. enpol.2007.08.023

Matsumoto N, Hondo H (2011) Analysis on employment effects of the introduction of renewable energy technologies using an extended input-output table. J Jpn Inst Energy 90:258-267. doi:10.3775/jie. 90.258 (In Japanese)

Matsuto T (2005) Analysis, design and evaluation of the municipal waste management system. Gihodo Shuppan, Tokyo. (In Japanese)

Ministry of Economy, Trade, and Industry (MITI) (2013) Reform of electric power system. www.enecho. meti.go.jp/category/electricity_and_gas/electric/system_reform.html. Accessed 24 June 2015. (In Japanese)

Ministry of Economy, Trade, and Industry (MITI), Material Processing Technology Commission (2010) A vision for machine parts and tooling industries—supplementary material-Course of action for our nation's materials process technology should adopt. http://www.meti.go.jp/policy/mono_info_ service/mono/sokeizai/tuihoban\%20.pdf. Accessed 24 June 2015. (In Japanese)

Ministry of Environment (MOE) (2011) Study of potential for the introduction of renewable energy (FY2010). (In Japanese)

Mizuho Information \& Research Institute (2009) Life cycle analysis of photovoltaic power generation system: examples, guidelines, and perspectives. (In Japanese)

Nakano S, Murano A, Washizu A (2015) Economic and environmental effects of utilizing unused Woody biomass. J Jpn Inst Energy 94:522-531. doi:10.3775/jie.94.522

National Institute of Science and Technology Policy (NISTEP) and MEXT (2013) Economic and environmental impact analysis for construction of renewable energy power plants by extended input-output table. Discussion Paper 096. (In Japanese)

Neuwahl F, Löschel A, Mongelli I, Delgado L (2008) Employment impacts of EU biofuels policy: combining bottom-up technology information and sectoral market simulations in an input-output framework. Ecol Econ 68:447-460. doi:10.1016/j.ecolecon.2008.04.018

New Energy Foundation (NEF) (2009) Basic survey of guide business for medium and small water-power utilization: Study of water-power resources for power generation by unutilized head (FY2008). http://www.enecho.meti.go.jp/category/electricity_and_gas/electric/hydroelectric/download/pdf/ ctelhy_012.pdf. Accessed 01 Feb 2013. (In Japanese)

New Energy and Industrial Technology Development Organization (NEDO) (2008) Final reports of field test projects on photovoltaic power generation (FY2007-2008). http://www.nedo.go.jp/library/ database_index.html. Accessed 01 Feb 2013. (In Japanese) 
New Energy and Industrial Technology Development Organization (NEDO), New Energy Foundation (NEF) (2002) 2001 report on a study to promote the development of geothermal energy and on the possibilities for its development (National strategic survey-No. 3). (In Japanese)

Niigata Prefecture (2010). http://www.pref.niigata.lg.jp/sangyoshinko/1271196038532.html. Accessed 01 Feb 2013. (In Japanese)

Park H, Heo E (2007) The direct and indirect household energy requirements in the Republic of Korea from 1980 to 2000: an input-output analysis. Energ Policy 35:2839-2851. doi:10.1016/j.enpol.2006. 10.002

Su B, Huang HC, Ang BW, Zhou P (2010) Input-output analysis of $\mathrm{CO}_{2}$ emissions embodied in trade: the effects of sector aggregation. Energ Econ 32:166-175. doi:10.1016/j.eneco.2009.07.010

Suzuki K, Uchiyama Y (2010) Quantifying the risk of an increase in the prices of non-energy products by combining the portfolio and input-output approaches. Energ Policy 38:5867-5877. doi:10.1016/j. enpol.2010.05.041

Tanaka S, Matsuto T (1998) Report on the development of the evaluation system that supports the integrated control of municipal waste. Sapporo, Graduate. School of Environmental Engineering, Hokkaido University. (In Japanese)

Tarancon MA, del Río P, Callejas Albiñana F (2010) Assessing the influence of manufacturing sectors on electricity demand: a cross-country input-output approach. Energ Policy 38:1900-1908. doi:10. 1016/j.enpol.2009.11.070

Wang C, Zhang W, Cai W, Xie X (2013) Employment impacts of CDM projects in China's power sector. Energ Policy 59:481-491. doi:10.1016/j.enpol.2013.04.010

Zeng L, Xu M, Liang S, Zeng S, Zhang T (2014) Revisiting drivers of energy intensity in China during 1997-2007: a structural decomposition analysis. Energ Policy 67:640-647. doi:10.1016/j.enpol. 2013.11.053

Zhou X, Shirakawa H, Lenzen M (2013) Aggregation effects in carbon footprint accounting using multiregion input-output analysis. In: Yu T, Chawla NV, Simoff S (eds) Computational Intelligent Data Analysis for Sustainable Development. CRC Press, Boca Raton 